\title{
ECONOMIA SOLIDÁRIA, ATIVISMO SOCIOPOLÍTICO E DEMOCRACIA
}

\section{Solidarity economy, socio-political activism and democracy}

\author{
Luiz Inácio Gaiger \\ (UNISINOS) \\ ORCID iD https://orcid.org/0000-0003-0241-7064
}

Informações do artigo

Recebido em 01/11/2019

Aceito em 10/04/2020

doi>: https://doi.org/10.25247/2447-861X.2020.n249.p83-110

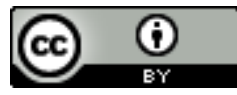

Esta obra está licenciada com uma Licença Creative Commons Atribuição 4.0 Internacional.

\section{Como ser citado (modelo ABNT)}

GAIGER, Luiz Inácio. Economia solidária, ativismo sociopolítico e democracia. Cadernos do CEAS: Revista Crítica de Humanidades. Salvador, v. 45, n. 249, p. 83110, jan./abr. 2020. DOI: https://doi.org/10.25247/2447861X.2020.n249.p83-110

\begin{abstract}
Resumo
O artigo examina a contribuição da Economia Solidária para os processos democráticos no Brasil, a partir da sua presença e atuação em movimentos e organizações de caráter social e político, tal como se encontram registradas nas bases de dados do Sistema Nacional de Informações sobre a Economia Solidária no Brasil. Após caracterizar o escopo temático e o grau de disseminação dessas formas de atuação, avalia sua convergência com questões de interesse coletivo e com procedimentos de caráter democrático. Discute também as relações entre os níveis de ativismo sociopolítico e as formas de gestão participativa adotada internamente pelos empreendimentos de economia solidária. Por fim, analisa os traços distintivos da liderança e seu possível distanciamento daqueles indivíduos cuja associação constitui a base dos empreendimentos. Ao tratar do ativismo sociopolítico de setores das classes populares, concluindo positivamente a respeito, o artigo tem como pano de fundo a questão democrática, o fato de que os cidadãos brasileiros permanecem profundamente desiguais do ponto de vista dos seus recursos econômicos, da discriminação imposta por padrões culturais ainda vigentes e da sua vulnerabilidade a círculos de dependência e subordinação política.
\end{abstract}

Palavras-chave: Autogestão. Classes Populares. Democracia. Economia Solidária. Política.

\section{Abstract}

The article examines the contribution of the Solidarity Economy to the democracy, from its presence and performance in social and political movements and organizations, as recorded in the databases of the National Information System on the Solidarity Economy in Brazil. After characterizing the scope and degree of dissemination of those forms of collective action, the article evaluates their convergence with social demands of common interest and with democratic procedures. It also discusses the relationship between the levels of socio-political activism and the forms of participatory management adopted internally by solidarity economy enterprises. Finally, it analyzes the distinctive traits of the leadership and their possible distancing from those individuals whose association forms the basis of the solidarity enterprises. By addressing the socio-political activism of popular classes, and concluding positively on this subject, the article has as its background the still challenging democratic question, the fact that Brazilian citizens remain profoundly unequal from the point of view of their economic resources, of the discrimination imposed by cultural patterns still in force and of their vulnerability to circles of dependence and political subordination.

Keywords: Self-management. Popular Classes. Democracy. Solidarity Economy. Politics. 


\section{Introdução}

Um dos fenômenos registrados durante o transcurso do período democrático iniciado no Brasil em 1985 foi a emergência progressiva de organizações com fins sociais e econômicos, de origem e cunho comunitário ou classista, que adotaram modalidades de gestão participativa, baseadas em princípios democráticos. Boa parte dessas iniciativas, levada à frente basicamente pela auto-organização de produtores, trabalhadores, usuários e consumidores de bens e serviços, perseverou e ganhou forma, identidade e oficialidade, disto resultando sua designação como organizações ou empreendimentos de Economia Solidária (CATTANI et al,2009). Seus fatores de impulsão apareceram modernamente desde a instauração do capitalismo no séc. XIX, dando lugar às vertentes associativas, mutualistas e cooperativas nas quais se edificou a experiência da Economia Social, em vários países do Norte e também ao Sul (DEFOURNY; NYSSENS, 2017). Desde esses primórdios, essas organizações caracterizavam-se por formas de gestão autônomas e participativas (SINGER, 1999).

Na atualidade da América Latina, a Economia Solidária tem sido associada às iniciativas que almejam gerar trabalho e renda, além de benefícios como maior qualidade de vida, reconhecimento e cidadania. Associações, grupos informais, cooperativas, empresas de autogestão, iniciativas locais nas áreas de serviços sociais, finanças solidárias e comércio justo, além de mecanismos correlatos de fomento e organizações representativas expandiram-se entre aqueles setores sociais à margem dos sistemas convencionais de ocupação e proteção social, ou crescentemente frustrados em suas aspirações individuais e coletivas (GAIGER et al, 2014).

Essas práticas converteram-se em objeto de estudo, motivando pesquisas quanto a seu sentido, seu papel de resistência social e suas virtudes emancipatórias. Ao longo do tempo, os entendimentos a respeito adotaram distintas ênfases: nos anos 1990, tais práticas foram vistas, sobretudo, como respostas emergenciais, lenitivas, frente à pobreza e ao desalento; novas abordagens (RAZETO, 1997; GUERRA, 2002; CATTANI et al, 2009; GAIGER, 2016) levaram a admitir, gradativamente, que o tema, por sua complexidade, tornaria inapropriado raciocinar em termos dualistas, contrapondo funcionalidade e alternatividade (LEITE, 2009). Com as posições céticas ou mais entusiastas assim mitigadas, cresceu a sensibilidade à natureza contraditória desses processos sociais e, a exemplo do 
cooperativismo, à compatibilidade entre papéis diversos passíveis de serem exercidos pela Economia Solidária: ser instrumento de compensação e de equilíbrio, ser forma de resistência à lógica dominante e ser espaço propulsor de alternatividade (NAMORADO, 2007: 10).

Nas Ciências Sociais, a Economia Solidária tem merecido atenção principalmente no âmbito de estudos sobre desigualdades, relações de trabalho, movimentos sociais e políticas públicas. Ela passou a integrar a agenda de encontros científicos, merecendo, ao mesmo tempo, resenhas temáticas e balanços, tanto das questões de pesquisa mais visadas quanto de pontos ainda merecedores de atenção (LEITE, 2009; Lima, 2012; GAIGER, FERRARINI; SCHIOCHET, 2018). Na medida de suas manifestações em diversos países e continentes (FONTENEAU et al, 2011; DEFOURNY; NYSSENS, 2017), alguns aspectos da Economia Solidária ganharam destaque nesse campo de estudos, como o valor da equidade entre aportes e retribuições dos membros, a primazia das decisões coletivas e o envolvimento social de seus integrantes, o que daria lugar a ativismos em variadas frentes è̀ sua presença em espaços públicos de debate e deliberação. Nos termos da linha interpretativa, cuja retomada constitui o cerne desse trabalho, a experiência de solidariedade veiculada pela Economia Solidária, especialmente quando lastreada em experiências anteriores de índole comunitária e associativa, ao estender-se a seus entornos estimularia práticas de reciprocidade nas quais as vivências concretas de gestão do bem comum conferem um novo valor às noções de justiça e de interesse público (LAVILLE, 2005; GAIGER, 2012). A Economia Solidária se constituiria, então, como um vetor democrático, ao induzir a participação via ação direta ou por dispositivos institucionais de representação. Ela viria, assim, a revitalizar ou propiciar espaços de construção de projetos coletivos, vinculados a diversos ativismos e a elementos teleológicos de transformação social.

Esse enfoque tem sido desenvolvido por nós com trabalhos de investigação empírica e de formulação teórica centrados no elo existente entre as dimensões empreendedora e solidária daquelas organizações, conforme ativem o princípio de reciprocidade (GAIGER, 2016). A vigência desse princípio torna as iniciativas solidárias propensas à adoção de práticas ativas de envolvimento em sua gestão e a engajamentos em questões de interesse público, renovando e ampliando, assim, as experiências de solidariedade social (LAVILLE, 2005).

Tendo em vista tais questões e parâmetros conceituais, esse artigo tem como propósito comparar, revisar e refinar conclusões de estudos anteriores sobre a presença sociopolítica de organizações e de atores da Economia Solidária (GAIGER, 2012; GAIGER et 
al,2014). A presença sociopolítica é aqui entendida lato sensu, como o envolvimento em ações ou em instâncias da esfera pública que digam respeito a demandas coletivas, à discussão de soluções e à formulação e implementação de políticas e ações congêneres. Para examiná-la, a pesquisa que dá suporte a esse artigo explorou fontes de informação representativas, a fim de dimensionar a participação política extramuros das iniciativas de Economia Solidária e avaliar sua presença na esfera pública, do ponto de vista da sociedade e da democracia - portanto, não apenas para os fins e a ótica da Economia Solidária. Julgamos oportuno examinar essas formas de participação com dados empíricos de um momento histórico recente, imediatamente anterior à crise institucional e ao refluxo que atinge a democracia brasileira nos dias atuais.

Uma contribuição singular, buscada por esse trabalho, decorre da insuficiência de dados representativos e conhecidos sobre a Economia Solidária, fato que caucionou uma preferência por estudos qualitativos. Esse padrão de análise, não obstante suas virtudes, retarda que se lance um olhar global, no sentido de dimensionar essas realidades no espectro amplo da economia, do mercado de trabalho e das estratégias dos trabalhadores. Tencionamos contribuir para o preenchimento desses hiatos mediante análises de dados pouco explorados pelos estudiosos da Economia Solidária e temas afins. Em primeiro lugar, trata-se da caracterização econômica, social e política de 20 mil empreendimentos econômicos solidários (EES), ${ }^{1}$ realizada no escopo do segundo Mapeamento Nacional da Economia Solidária no Brasil (2010-2013). Esse cabedal de informações permite explorações em vários sentidos, a exemplo de estudos anteriormente realizados sobre dados do primeiro Mapeamento Nacional (2005-2007), cujos resultados, do ponto de vista da participação sociopolítica (GAIGER, 2012), compõem o ponto de partida da análise aqui proposta.

O tratamento das informações e as análises gerais dos dados do segundo Mapeamento estiveram a cargo de uma equipe liderada pelo autor desse artigo. Além de facilitar o manuseio das informações, essas atividades culminaram, em 2013, com uma pesquisa amostral associada aos dados do segundo Mapeamento, mas desta vez dirigida aos sócios e sócias dos EES. Não obstante tenham sido abertas ao acesso público, como parte do Sistema de Informações sobre a Economia Solidária (SIES), os dados têm sido

\footnotetext{
1 Utilizaremos a sigla EES ao referirmos o conceito e a unidade de análise dos Mapeamentos.
} 
esporadicamente utilizados pela comunidade científica. Eles permitem muitos estudos tópicos e análises de ordem geral, a começar pela demografia dos EES e dos seus integrantes, quanto a seu perfil social e econômico e, igualmente, à sua atuação política. ${ }^{2}$

A pesquisa amostral sobre sócios e sócias teve como foco as circunstâncias que levaram indivíduos a se associar e perseverar em empreendimentos solidários, além das repercussões dessa escolha sobre suas ocupações, rendas e formas de participação nos espaços coletivos próprios da Economia Solidária, naqueles de mobilização social e na esfera pública, via estruturas paritárias de participação, como os conselhos de desenvolvimento. A pesquisa captou, igualmente, algumas percepções subjetivas dos informantes sobre a economia solidária, a sociedade e a política. Contém, assim, um manancial de dados que permitem retomar questões examinadas anteriormente e correlacionar os perfis e itinerários dos integrantes natos da Economia Solidária a características e a práticas de cooperação interna e externa dos EES. Faculta, então, verificar em quais tipos de empreendimentos a participação sociopolítica é favorecida e com quais desdobramentos para o ativismo cívico de seus integrantes.

Metodologicamente, esse trabalho propõe-se a exemplificar como o escrutínio de dados abrangentes serve ao balizamento de questões e de linhas argumentativas sobre o papel da Economia Solidária, na política e em outras esferas da vida social. No plano teórico, seu objetivo é focalizar a Economia Solidária do ponto de vista das intersecções entre a participação popular e a institucionalidade política. Incide, assim, na questão democrática, no fato de que os cidadãos brasileiros permanecem profundamente desiguais, do ponto de vista dos seus recursos econômicos, da discriminação imposta por padrões culturais ainda vigentes e da sua vulnerabilidade a círculos de dependência e subordinação política.

A primeira seção do artigo apresenta uma caracterização geral da participação dos EES na arena pública, através de redes, fóruns, movimentos e iniciativas comunitárias. A seguir, examinam-se alguns aspectos dessa participação, no sentido de evidenciar sua relação com questões de interesse comum e com a satisfação de demandas coletivas, sem

\footnotetext{
2 Boa parte da documentação relativa ao segundo mapeamento e à pesquisa amostral, incluindo aspectos metodológicos, publicações e acesso aos dados através de um atlas digital está disponível no site do Projeto Sies: Link. Em convênio com o Departamento Intersindical de Estatística e Estudos Socioeconômicos (DIEESE), a SENAES disponibilizou as informações ao Observatório Nacional da Economia Solidária e Cooperativa, no qual se encontram indicadores, estudos setoriais e um mapa interativo: Link.
} 
deixar que interesses particularistas ou corporativas prevaleçam. A terceira seção do artigo diz respeito às correlações entre o nível de envolvimento sociopolítico dos EES e a presença, em sua dinâmica interna, de mecanismos de participação e autogestão. Demonstrar incidências positivas entre esses aspectos significa corroborar o caráter duplamente engajado dos EES, em suas práticas intramuros e em suas relações com a sociedade. Um último ponto será considerado na seção seguinte, quanto à possível existência de uma camada social de associados, atuante em frentes de participação sociopolítica, que se distinguiria e tendencialmente se poderia apartar da base social dos EES, essa ficando, então, alheia aos problemas em debate na sociedade e às formas de ação coletiva. O artigo se encerra com uma breve recapitulação dos principais resultados obtidos ao longo da análise, seguida de reflexões sobre as contribuições da Economia Solidária para o avanço da democracia e, nos dias atuais, para a resistência democrática que se faz necessária.

\section{Características gerais da participação sociopolítica}

Pessoas acostumadas a transitar entre as organizações de Economia Solidária, por certo, não teriam dúvidas quanto ao envolvimento de seus diversos atores em movimentos sociais mais amplos e na arena pública. Disso provavelmente não lhes faltariam exemplos, pois a Economia Solidária é pródiga em iniciativas e se tem caracterizado por criar ou apoiar movimentos, multiplicar instâncias representativas e promover encontros locais, regionais e nacionais. ${ }^{3}$ Quanto a isso, os dados gerais do segundo Mapeamento se aproximam do padrão já indicado pelo primeiro Mapeamento:

a) No primeiro Mapeamento, $46 \%{ }^{4}$ dos EES haviam declarado participar de alguma rede ou fórum de articulação ou representação, caindo esse percentual para $40 \%$ no

3 Em junho de 2019, poucos meses após a entrada em cena do novo governo federal, redes sociais anunciaram um Seminário Nacional do Cooperativismo e da Economia Solidária, promovido pela UNICOPAS - União Nacional das Organizações Cooperativistas Solidárias, a realizar-se na Câmara dos Deputados com o fim de estabelecer debates com parlamentares, isto no bojo de um encontro de três dias - de Formação Nacional em Incidência Política, Monitoramento e Construção de Políticas Públicas. Ao mesmo tempo, noticiava-se a entrada no Senado de uma proposta de emenda à Constituição (PEC 69/2019) com o objetivo de inserir a Economia Solidária entre os princípios da ordem econômica. Ademais, fruto de pressões de várias frentes e após transitar por vários anos, em 10/07/2019 foi aprovado por unanimidade, pela Comissão de Desenvolvimento Regional do Senado Federal, o Projeto de Lei 137/2017 que dispõe sobre a política nacional de Economia Solidária, seguindo então para a Comissão de Assuntos Econômicos.

4 Os valores foram arredondados, exceto quando a primeira casa decimal é igual a 5. 
segundo mapeamento; as redes e fóruns referem-se a articulações próprias da Economia Solidária, a uniões ou associações de EES, a federações cooperativas, a conselhos de gestão e fóruns de participação em política públicas, entre outros;

b) A participação em ações sociais ou comunitárias decresce de $58 \%$ para $46 \%$; os temas em causa compreendem a saúde, moradia, educação, trabalho, redução da violência, assistência social, segurança alimentar, meio-ambiente, esporte e lazer, cultura e outros;

c) Já a participação em movimentos sociais, populares e sindicais ${ }^{5}$ eleva-se ligeiramente de 57\% para 58\%; o leque de movimentos é bastante amplo, incluindo as lutas pela terra e pela agricultura familiar, o sindicalismo urbano e rural, as lutas por moradia, os movimentos étnico-raciais, de mulheres e gênero, movimentos de catadores e recicladores, a defesa de direitos humanos, movimentos de combate à fome, movimentos ambientalistas ou de agroecologia, e assim por diante.

Como frentes de atuação mais citadas nos três casos, salientam-se os fóruns e redes próprias de Economia Solidária, os conselhos de gestão e fóruns de participação em políticas públicas, os movimentos sindicais, as lutas pela terra ou da agricultura familiar, seguidas de ações diversas em prol do meio ambiente, da educação ou da saúde. ${ }^{6}$

Contudo, precisamente por ser essa uma percepção comum, convém examinar os percentuais e as formas de participação em pormenores, sem generalizações a partir de casos individuais ou daqueles segmentos específicos que eventualmente se destaquem nesse aspecto. Para maior segurança analítica, preferimos adotar um conjunto de hipóteses negativas, que vão no sentido contrário ao da participação presumida, com objetivo de testálas uma a uma à luz das informações disponíveis nas bases de dados do SIES sobre os aspectos em tela. Como já sucedeu em análises anteriores do primeiro Mapeamento (GAIGER, 2012), as conclusões dependerão do grau de rejeição - ou de confirmação - de cada uma dessas hipóteses. A primeira delas refere-se à caracterização geral que nos ocupa aqui:

\footnotetext{
5 Na primeira menção, as variáveis do Mapeamento são reproduzidas em sua formulação original completa, sendo abreviadas a seguir.

${ }^{6}$ As questões sobre os tipos de participação eram de resposta múltipla.
} 
Hipótese 1: a participação sociopolítica dos EES não é generalizada, mas momentânea ou localizada, explicando-se por circunstâncias particulares e transitórias.

A hipótese foi testada de diferentes ângulos, para averiguar se a participação não se concentra em algum tipo específico de EES, porventura vinculado a alguma região do país, a uma área de atuação (rural ou urbana), a uma forma de organização (cooperativa, associação, etc.), a algum tipo de atividade econômica (produção, crédito, etc.), a um tempo determinado de funcionamento ou, ainda, ao porte dos EES, estimado pelo número de pessoas associadas.

No que diz respeito à distribuição regional, constata-se uma dispersão nacional dos EES participativos, embora com um percentual proporcionalmente maior, na região Nordeste, de EES com participação em movimentos sociais e em ações sociais e comunitárias, como indicam os gráficos da Figura 1.7 De modo geral, os dados apontam que EES participativos existem em percentuais consideráveis em todo o território nacional, independentemente da forma de organização, da atividade econômica, do tempo de funcionamento e do porte. Ao mesmo tempo, se sobressai um padrão numericamente predominante de EES participativos, ligado às grandes cifras do Mapeamento: a Região Nordeste, o meio rural, as associações, os EES de produção e de consumo e uso coletivo de bens e equipamentos, os EES iniciados no período 1993-2007, aqueles com 21 ou mais membros associados e, ainda, os EES com participação em movimentos sociais. Contrasta com ele um segundo padrão, de pequenas cifras, formado principalmente por EES de troca, prestação de trabalho ou serviços (e de finanças solidárias), mais presentes em meio urbano (ou misto), com um segmento de EES anterior a 1989, predominando aqueles com mais de 50 membros e com foco de atuação em ações sociais e comunitárias.

7 É preciso considerar que o Nordeste comporta $41 \%$ dos EES mapeados, enquanto as demais regiões oscilam entre $17 \%(\mathrm{Sul}), 16 \%$ (Sudeste e Norte) e 10\% (Centro-Oeste). 
Figura 1: EES participativos por Regiões do País

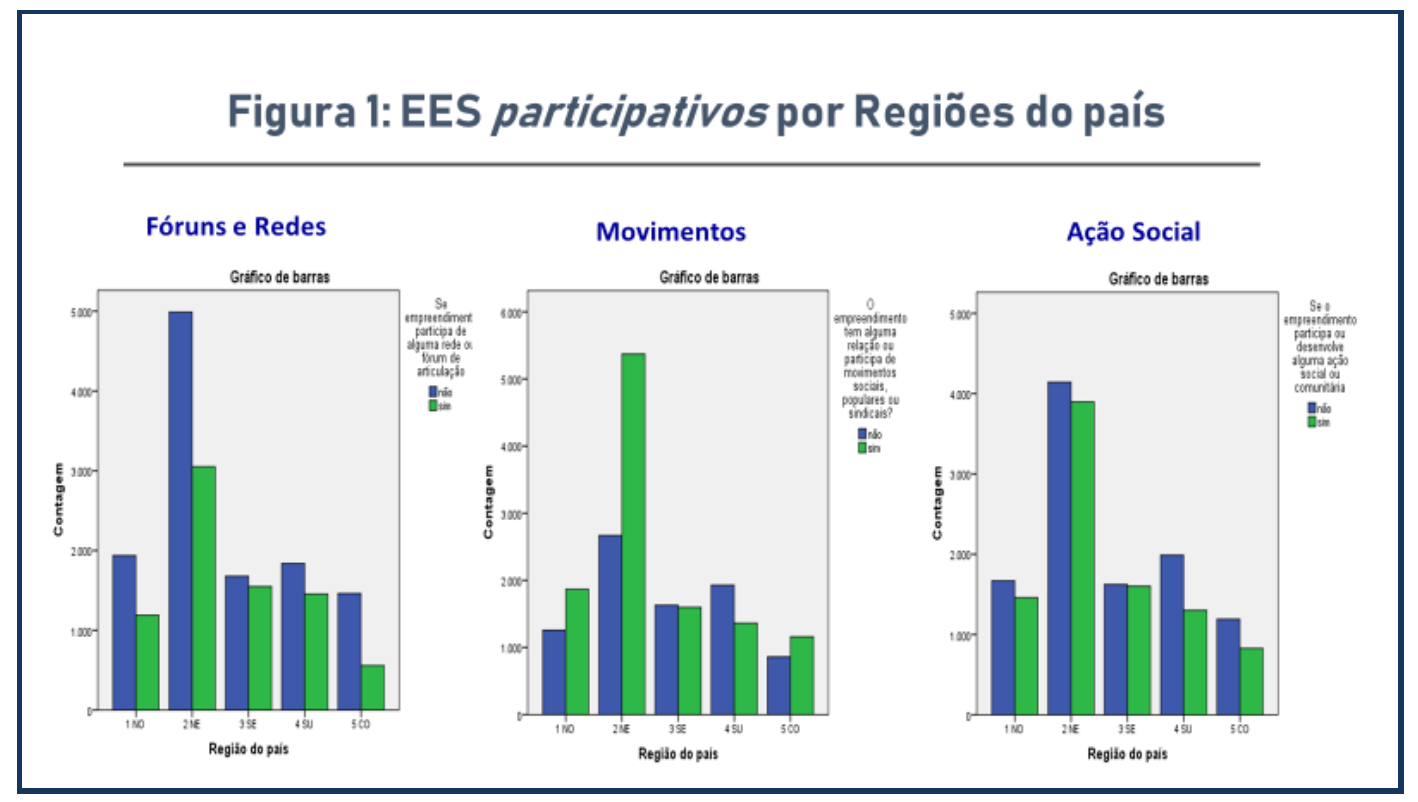

Fonte: segundo Mapeamento Nacional da Economia Solidária

Fez-se, ainda, uma análise dos EES que apresentam envolvimentos sociopolíticos concomitantes: eles seguem o padrão geral dos EES participativos, destacando-se novamente a Região Nordeste, a área rural e as associações. Há ligeira queda na presença de EES informais nesse segmento $(26 \%)$, comparada com a sua presença no Mapeamento $(30,5 \%)$. Verificou-se, ainda, que os EES envolvidos em várias frentes dispõem com mais frequência de computador (60\%) e de internet (57\%), diante das cifras gerais ( $46 \%$ e 42\%), o que faz sentido por serem tais equipamentos um suporte para conexões à distância, facilitando a participação sociopolítica dos EES. Assim, essa participação não se mostra momentânea ou localizada, tampouco explica-se por circunstâncias particulares ou transitórias. Fica rejeitada a primeira hipótese.

\section{O caráter republicano da participação}

Uma das debilidades reconhecidamente flagrante do sistema político brasileiro é a permanência de padrões particularistas e clientelistas no processo de eleição dos representantes, de gestão das prioridades de governo e de implantação das políticas de Estado. O valor, e mesmo a noção de bem público, ficam esmaecidos, confundidos a todo instante com motivações momentâneas, setoriais ou meramente privadas, perdendo-se, 
assim, na ciranda das transações de interesses, da base ao alto da pirâmide em que se configura o sistema político. ${ }^{8}$

Considerando esse estado de coisas, torna-se relevante averiguar se a participação sociopolítica da Economia Solidária está direcionada a temas de interesse comum que extrapolam ou mesmo contradizem seus interesses de natureza privada. Ademais, explorando os dados do segundo Mapeamento Nacional, conviria averiguar se as formas de participação dos EES observam e valorizam princípios e procedimentos democráticos.

Uma análise minuciosa a esse respeito foi realizada com base nas informações do primeiro Mapeamento (concluído em 2007), atestando o caráter público da participação sociopolítica dos EES (GAIGER, 2012). Dada a evolução da conjuntura brasileira nos anos 2000 e o intervalo de seis anos até o final do segundo Mapeamento (concluído em 2013), mudanças significativas no padrão apurado não seriam de esperar-se; apenas teriam cabimento, no plano interpretativo, com indícios consistentes. Por isso, buscando manter o mesmo rigor analítico, formulamos duas hipóteses negativas; a primeira delas, de caráter abrangente:

Hipótese 2: interesses corporativos (limitados a grupos singulares de indivíduos ou de organizações) ou motivações utilitaristas (voltadas a vantagens e benefícios de grupo ou indivíduos) determinam a atuação sociopolítica dos EES.

As primeiras verificações a respeito se debruçaram sobre os tipos de organização social e política em que os EES mais se envolvem e sobre as demandas correlatas mais visadas. Em conclusão dessas análises, mantém-se o padrão do primeiro Mapeamento: a) o envolvimento em fóruns e redes abrange uma panóplia de situações, com destaque a entidades situadas na órbita da Economia Solidária (45\%) e aos conselhos de desenvolvimento e similares (23\%). Bastante diversos, os temas em foco transitam de questões ligadas a categorias sociais ou setores econômicos específicos (agroecologia, apicultura, artesanato, catadores, jovens, crianças, idosos) a causas de interesse geral (água, agricultura, assistência social, cultura, saúde, segurança, desenvolvimento local); b) a

8 Uma análise histórica, ao mesmo tempo ampla e minuciosa, sob a ótica dos influxos e refluxos das capacidades estatais sob regimes políticos oscilantes de autoritarismo e democracia no Brasil, é oferecida por Pinho (2019). 
participação em movimentos sociais assume um caráter classista, como antes apontado (movimento sindical: $58 \%$ das indicações; lutas pela terra e vinculadas à agricultura: $36 \%$ ), mas causas gerais ou transversais também figuram (movimento popular e comunitário: 28\%; movimento ambientalista e de agroecologia: 18\%; movimento religioso ou pastoral: $23 \%$ ); c) quanto à participação em ações sociais e comunitárias, seu sentido por vezes presumivelmente altruísta e universal confirma-se nos campos de atuação mais frequentes, ainda que caiba reconhecer os objetivos dos EES de materializar as conquistas no âmbito local em que estão inseridos (meio ambiente: 46\%; educação: 44\%; saúde: $37 \%$; cultura: $33 \%)$.

Uma segunda ronda de análise incidiu sobre as dificuldades econômicas dos EES passíveis de motivar suas iniciativas e, além disso, restringi-las a essa órbita. Em função dos dados disponíveis, examinou-se a influência da necessidade de crédito ou financiamento dos EES e da dificuldade de obtenção de crédito ou financiamento, como possíveis determinantes dos envolvimentos sociopolíticos. Cabe mencionar que esses problemas afetam uma fração considerável dos EES mapeados: $62 \%$ deles declararam ter necessidade e $65 \%$, dificuldade de acesso ao crédito ou a financiamentos. Pois bem, apenas a participação em movimentos sociais é mais frequente entre os EES com necessidade de crédito $(64 \%$, contra $44 \%$ para aqueles sem necessidade) e entre os EES com dificuldade de acesso ao crédito $(67 \%$, contra $57 \%$ para aqueles sem dificuldade). Resolver esses problemas se mostra, então, uma possível razão de tais envolvimentos, embora o percentual médio de EES sem tais problemas que participam de movimentos sociais seja de 50,5\%, não muito abaixo do percentual geral dos EES mapeados que declaram dita participação, de $58 \%$.

No Mapeamento inexistem informações sobre movimentos relacionados diretamente a essas questões financeiras, de modo que as inferências a respeito apenas podem ser indiretas. É sabido que demandas de crédito integram a pauta do movimento sindical, das organizações de agricultura familiar, da luta pela terra, bem com o rol de reivindicações dos catadores, entre outros. Trata-se, em todos esses casos, de uma forma coletiva de resolver ou minorar tais problemas, cujos resultados materializam-se via de regra por meio de políticas públicas ou de medidas institucionais de caráter abrangente, sem se limitar aos indivíduos ou organizações que vocalizam as demandas. Ademais, seria plausível imaginar que a participação sociopolítica, especialmente via movimentos sociais, conduza ao contato com experiências de reivindicação bem-sucedidas e com alternativas correlatas de 
resolução de dificuldades financeiras, elevando, assim, a consciência e as expectativas a respeito. Ou seja, mais do que um processo unidirecional e cíclico de "demanda reivindicação - mobilização - ganhos - desmobilização", podemos estar diante de uma dinâmica em espiral que conduz os EES a manterem-se ativos e inovarem em suas formas de mobilização, à medida que a práxis sociopolítica propicia aprendizagens, brinda recompensas concretas e suscita novas aspirações. ${ }^{9}$

Também foi examinada a possível relação entre participação e dificuldades de comercialização ou vendas. Essas dificuldades variam, conforme se trate de EES com atividade principal de produção, comercialização ou prestação de trabalho ou serviços. Sua presença entre os EES fica globalmente em um patamar de $33 \%$ a $51 \%$. De modo geral, as frequências de participação sociopolítica crescem entre os EES com dificuldades de comercialização, contudo, sem propriamente se concentrarem nesse polo. A forma de participação sociopolítica que apresenta crescimento mais visível é aquela em fóruns e redes de articulação ou representação (incremento médio de $11 \%$ em relação aos EES sem dificuldades de comercialização), seguida da participação em ações sociais e comunitárias (incremento médio de 7,5\%).

Que uma coisa leve à outra, nos dois sentidos, não é improvável; que os motivos subjacentes sejam particularistas, já não se poderia dizer, pois tais envolvimentos, em regra, não possuem objetivos direta ou exclusivamente econômicos, afetos a questões comerciais. ${ }^{10}$ As motivações podem ter sinais contrários, seja um altruísmo praticado a despeito dos problemas econômicos dos EES, seja uma busca de soluções de comercialização. Assim, se a participação em movimentos sociais - de natureza muito diversa, como vimos - não é especialmente motivada por questões de comercialização, essas últimas poderiam motivar a presença em fóruns e redes de articulação e representação, dado o cenário de múltiplas inserções dos EES e, sobretudo, de busca de viabilização econômica através de soluções coletivas. Globalmente, portanto, não se deve excluir que os problemas de comercialização, ao lado de outros, sejam resolvidos pela via sociopolítica, mas tampouco

9 O papel motor de circuitos virtuosos que propulsionam os EES foi identificado na primeira pesquisa nacional a respeito no Brasil (GAIGER, 2004, p. 23-25).

${ }^{10}$ A variável do Mapeamento em questão (157) não deve ser confundida com outra (26), que se refere à participação dos EES em rede de produção, comercialização, consumo ou crédito; portanto, com objetivos econômicos. Ela será examinada adiante. 
que motivações desinteressadas em tais envolvimentos prevaleçam, ou, ainda, que EES mais consolidados e autossuficientes, sem aqueles problemas, sejam mais participativos. ${ }^{11}$

Mais decisivo é o fato de que a estratégia básica acionada, via redes movimentalistas, em regra traz resultados para uma determinada coletividade ou grupo de EES, não a demandas individuais. Por isso, dentro das possibilidades é conveniente averiguar se a resolução de problemas econômicos particulares ocorre via mercado, por estruturas públicas ou pelos canais da Economia Solidária. Com esse fim, consideramos os casos de busca e obtenção de crédito, atentando para as fontes do crédito concedido. Em primeiro lugar, entre os EES que buscaram e obtiveram crédito a participação sociopolítica é mais frequente em relação aos percentuais gerais, especialmente em fóruns e redes $(53 \% \times 40 \%)$ e em movimentos sociais $(67 \% \times 58 \%)$, nesse segundo caso, mesmo quando não conseguiram o crédito $(65,1 \%)$. Assim, retomando o raciocínio anterior, conclui-se por uma relação entre participação e busca de recursos financeiros, sinalizando-se que essa estratégia é razoavelmente exitosa. Como essa relação positiva também se estende à participação em ações sociais e comunitárias, sinal de integração dos EES nesse âmbito, tem-se um contexto geral de emulação e militância social e política.

Quanto às fontes de crédito, são mais frequentes as participações sociopolíticas dos EES no caso de instituições do setor público, Ongs, Ocips e cooperativas de crédito, ao contrário do observado em EES que recorreram com sucesso a bancos privados, cujas participações decrescem. No caso das cooperativas de crédito, o percentual de participação sociopolítica dos EES sobe quase $15 \%$, de modo similar às Ongs e Ocips. Mais saliente é o caso dos fundos solidários e bancos comunitários, quando o percentual se eleva em $22 \%$. 0 que temos, então, como modelo principal, não é uma corrida individual por recursos, mas a constituição de um mercado sociopolítico no qual os objetivos econômicos dos EES fomentam estratégias coletivas, através de redes e associações mais amplas, incluído o poder público. De mais a mais, voltando à última questão em análise, quem obteve crédito, independentemente da fonte, tende a participar mais do que os outros, o que demonstraria

\footnotetext{
11 Uma análise mais detalhada, embora possivelmente inconclusiva a esse respeito, poderia ser feita examinando-se, caso a caso, os tipos de fóruns, movimentos e ações sociais.
} 
que essa conquista, sendo um motivo inicial, é também um fator presumível de valorização das estratégias coletivas.

À guisa de prova dos nove, uma análise complementar foi estendida à participação em redes econômicas de produção, comercialização, consumo ou crédito, declarada por $17,7 \%$ dos EES. Eles se inserem nessas redes econômicas apenas em função de seus interesses mais diretos e imediatos? Explorando os dados disponíveis, as cooperativas apresentam maior participação nas estruturas correspondentes, tais como cooperativas centrais e complexos cooperativos, ou quando se referem a atividades específicas, como as redes de crédito ou finanças solidárias. Contudo, elas participam também de redes mais amplas de comercialização ou produção e de centrais de comercialização, não se limitam às estruturas do seu setor específico. Já as redes de crédito ou finanças solidárias são mais visadas pelos EES cuja atuação é desse ramo. Contudo, a despeito da sua atividade principal, há EES participando de várias redes; em especial, aqueles de trocas de produtos ou serviços e aqueles de trabalho ou prestação de serviços apresentam várias participações simultâneas.

Por fim, examinamos a hipótese de que o viés particularista dos EES tivesse relação não com seus objetivos econômicos, mas sim com a composição do seu quadro social, o que canalizaria as ações para demandas específicas, em detrimento de questões mais gerais. Os dados a respeito indicam que os EES que mais se envolvem em lutas étnico-raciais são aqueles com predominância de negros (29\% deles) e indígenas $(69 \%)$, sendo escassa a participação dos demais. Do mesmo modo, há uma acentuada participação nessas lutas de EES com predominância de povos indígenas (54\%), população negra (41\%), quilombolas $(51 \%)$ e comunidades de terreiro (48\%). Movimentos específicos afetos a categorias sociais também atraem EES de catadores (87\%) e desempregados (9\%). Ao lado disso, há envolvimentos de diversos EES em questões de interesse geral. Os movimentos ambientalistas e de agroecologia, por exemplo, atraem EES com predominância de catadores (48\% deles), técnicos de nível superior (30\%), artistas (20\%), agricultores familiares (17\%), assentados (13,5\%) e artesãos (13\%), entre outros. As estratégias dos EES focalizam inserções específicas, sem descartarem outras frentes, de modo que a multiplicidade de causas e enlaces se mostra a lógica dominante. 


\section{Autogestão e participação sociopolítica}

Pelo visto até aqui, os EES envolvem-se em causas específicas e genéricas, que se combinam dentro de uma estratégia coletiva de organização e de incidência na esfera pública, ou frente aos demais atores sociais. Apesar de alguns pontos permanecerem merecedores de pesquisas específicas mais detalhadas, à luz dos dados não podemos validar a hipótese 2. No entanto, resta uma questão relacionada ao grau de autonomia dos EES para tomarem suas iniciativas. Aqui, entra em jogo o tipo de gestão dos EES e o nível de influência externa que sofrem, o que nos leva, inicialmente, a examinar uma terceira hipótese negativa:

Hipótese 3: agentes externos exercem influência indutora decisiva sobre a participação sociopolítica dos empreendimentos.

O recebimento de apoios externos pelos EES certamente é um dos objetivos da sua participação sociopolítica e, por seu turno, deve retroalimentá-la. Uma correlação ${ }^{12}$ positiva entre ambos é de esperar-se e, como tal, não retira a autenticidade da participação. Contudo, discrepâncias gritantes de participação, entre EES que recebem apoio externo e EES que não recebem, poderiam significar uma influência decisiva dos agentes externos, em prejuízo da autonomia decisória e da eventual propensão interna dos EES a não participar.

Não há dados suficientemente esclarecedores dessa questão no Mapeamento, o que nos leva a explorar algumas possibilidades de inferência. A primeira consiste em averiguar se o acesso dos EES a assessorias ou apoios externos é um requisito ou um condicionante forte de sua participação sociopolítica. Nota-se, então, que os três tipos gerais de participação que temos considerado são mais frequentes entre os EES que receberam algum tipo de apoio externo (no total, $75 \%$ dos EES), com destaque à atuação em fóruns e redes (incremento de 20,5\% em relação aos EES sem apoios externos), sobretudo quando o apoio consistiu em assessoria sociopolítica (23\%) ou em incubação (20\%). No entanto, entre os EES sem apoio $27 \%$ participam de redes e fóruns, $49 \%$ tomam parte em movimentos e $35,5 \%$, em ações sociais e comunitárias. O apoio externo tem correlação positiva com a participação, mas não se mostra um fator condicionante.

${ }^{12}$ Entendida em sentido amplo, de simultaneidade ao menos parcial observada entre eventos, fatos ou características, e não em sentido estrito de correlação ou covariação, medida por testes estatísticos. 
Pode-se indagar se o tipo de apoio recebido exerce um efeito indutor relevante. Vêse que assessoria sociopolítica, marketing e comercialização, diagnósticos e estudos de viabilidade econômica, ao lado dos processos de incubação, estão associados à maior frequência de participação sociopolítica, com algumas exceções. Porém, também entre os EES apoiados, mas privados daquelas assessorias específicas, os percentuais de participação são consideráveis. Um efeito indutor, mas não decisivo, parece, então, ser exercido por organizações e agentes externos, o que se coaduna logicamente com os propósitos de variadas entidades civis, entes públicos e organizações da Economia Solidária, cujo trabalho de fomento procura fortalecer e aportar instrumentos aos EES, o que inclui quebrar o seu isolamento.

Uma questão mais fundamental reside em saber quem toma as decisões, em nome dos EES, e com qual grau de participação dos seus membros. Regra geral, eles se distinguem das empresas convencionais por suas práticas de gestão coletiva, cujo acionamento representa um trunfo a favor do desempenho econômico, conferindo-lhe peculiaridades advindas da simbiose entre sua lógica solidária e sua lógica empreendedora (GAIGER, 2007). Se a participação externa dos EES decorre desta mesma racionalidade, não sendo algo estranho à sua natureza, é de esperar-se que a existência de indicadores de autogestão se alinhe com ela, do ponto de vista das formas e do grau de participação sociopolítica. Até certo ponto, os dados do Mapeamento permitem discernir dispositivos internos com esse caráter e correlacioná-los com maior ou menor probabilidade de participação sociopolítica. Uma vez mais, o exame dessa matéria será feito a partir de uma hipótese negativa:

Hipótese 4: o grau de participação sociopolítica dos EES não está associado ao seu nível de autogestão, nem a seus instrumentos de participação coletiva nas decisões.

De maneira similar à análise dos dados do primeiro mapeamento, em primeiro lugar verificamos em que medida a presença de instâncias coletivas de decisão ou coordenação nos EES se reflete em maior frequência de participação externa, sociopolítica. Conforme indica a tabela 1, há uma convergência global entre os dois grupos de variáveis selecionadas: quando uma determinada instância coletiva existe nos EES, o percentual daqueles que participam sociopoliticamente é maior; a inexistência daquela instância redunda em menor ocorrência 
de participação. Assim, os pares sim/sim ou não/não predominam em todos os cruzamentos e forma destacados em cor verde quando superam $60 \% .{ }^{13}$

Tabela 1 - Percentuais de participação e de não-participação sociopolítica dos EES, conforme possuam ou não instâncias de direção e coordenação coletivas

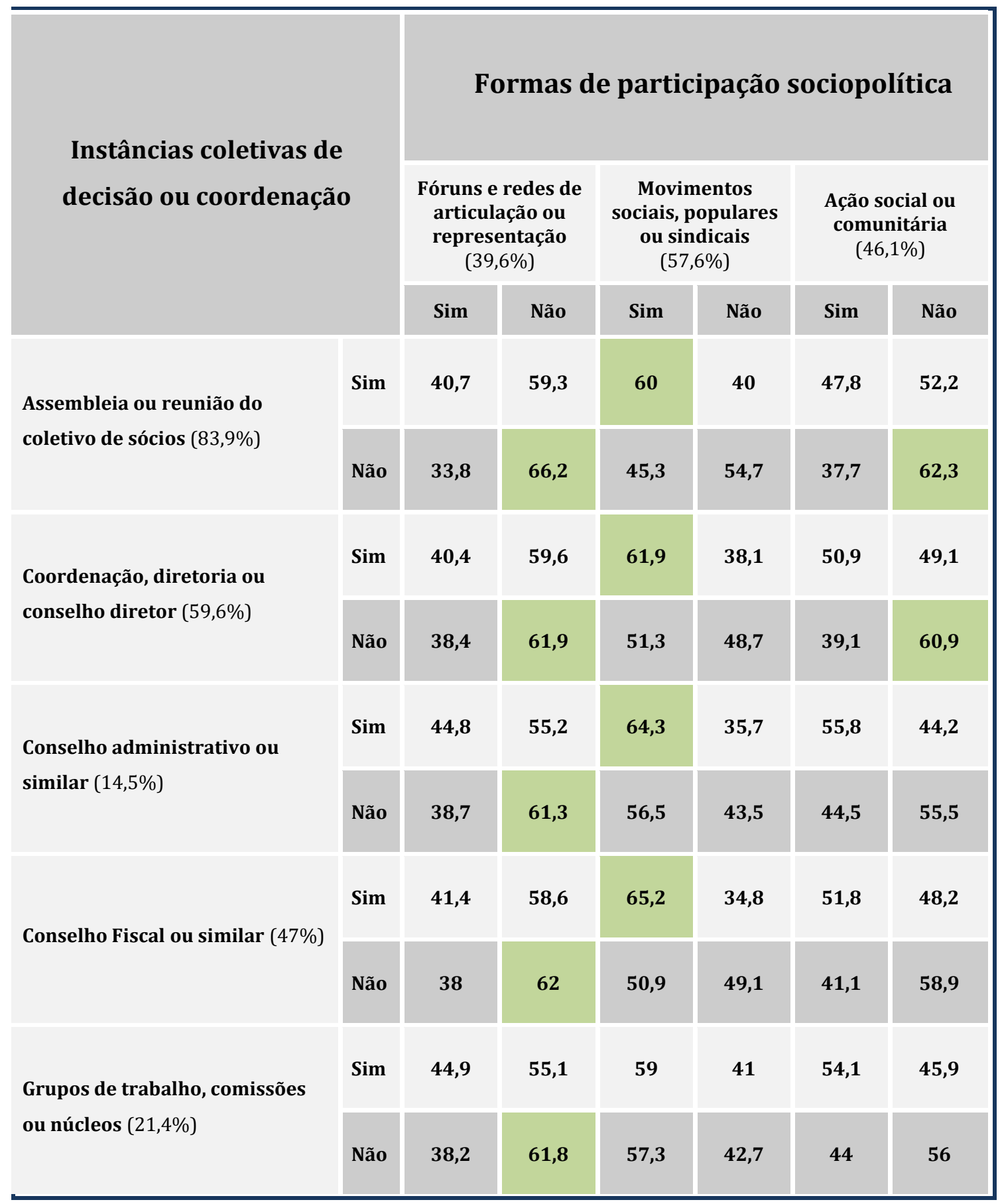

Fonte: segundo Mapeamento Nacional

\footnotetext{
${ }^{13}$ A superioridade dos números em geral não é simultânea para os dois pares por conta dos percentuais de cada variável, em linha e coluna, que afetam as casas correspondentes para baixo quando encerram valores menores.
} 
Uma segunda etapa de análise incidiu sobre as práticas de participação dos associados nas decisões internas dos EES, conforme a tabela 2:

Tabela 2 - Percentuais de participação e de não-participação sociopolítica dos EES, conforme possuam ou não formas de participação das sócias e sócios nas decisões

\begin{tabular}{|c|c|c|c|c|c|c|c|}
\hline \multirow{3}{*}{\multicolumn{2}{|c|}{$\begin{array}{l}\text { Formas de participação dos } \\
\text { sócios nas decisões dos EES }\end{array}$}} & \multicolumn{6}{|c|}{ Formas de participação sociopolítica } \\
\hline & & \multicolumn{2}{|c|}{$\begin{array}{l}\text { Fóruns e redes de } \\
\text { articulação ou } \\
\text { representação } \\
(39,6 \%)\end{array}$} & \multicolumn{2}{|c|}{$\begin{array}{l}\text { Movimentos } \\
\text { sociais, populares } \\
\text { ou sindicais } \\
(57,6 \%)\end{array}$} & \multicolumn{2}{|c|}{$\begin{array}{l}\text { Ação social ou } \\
\text { comunitária } \\
(46,1 \%)\end{array}$} \\
\hline & & Sim & Não & Sim & Não & Sim & Não \\
\hline \multirow{2}{*}{$\begin{array}{l}\text { Escolha da diretoria em } \\
\text { assembleia ou reunião do } \\
\text { coletivo }(67,9 \%)\end{array}$} & Sim & 40,4 & 59,6 & 62,8 & 37,2 & 49,7 & 50,3 \\
\hline & Não & 38 & 62 & 46,7 & 53,3 & 38,5 & 61,5 \\
\hline \multirow{2}{*}{$\begin{array}{l}\text { Contratações e remunerações } \\
\text { definidas em assembleia ou } \\
\text { reunião do coletivo }(29,5 \%)\end{array}$} & Sim & 44 & 56 & 63,2 & 36,8 & 51,9 & 48,1 \\
\hline & Não & 37,7 & 62,3 & 55,3 & 44,7 & 43,7 & 56,3 \\
\hline \multirow{2}{*}{$\begin{array}{l}\text { Plano de trabalho ou } \\
\text { planejamento estratégico } \\
\text { definido em assembleia ou } \\
\text { reunião do coletivo }(50,7 \%)\end{array}$} & Sim & 46,6 & 53,4 & 61,1 & 38,9 & 52,2 & 47,8 \\
\hline & Não & 32,4 & 67,6 & 54,1 & 45,9 & 39,9 & 60,1 \\
\hline \multirow{2}{*}{$\begin{array}{l}\text { Prestação de contas aos sócios } \\
\text { em assembleia ou reunião do } \\
\text { coletivo }(80,3 \%)\end{array}$} & Sim & 41,1 & 58,9 & 60,4 & 39,6 & 48,5 & $\mathbf{5 1 , 5}$ \\
\hline & Não & 33,4 & 66,6 & 46,4 & 53,6 & 36,5 & 63,5 \\
\hline \multirow{2}{*}{$\begin{array}{l}\text { Acesso aos registros e } \\
\text { informações do EES }(64,6 \%)\end{array}$} & Sim & 42,1 & $\mathbf{5 7 , 9}$ & 60,8 & 39,2 & 49,1 & 59,9 \\
\hline & Não & 36,5 & 63,5 & 53,5 & 46,5 & 42,3 & 57,7 \\
\hline \multirow{2}{*}{$\begin{array}{l}\text { Participação dos sócios nas } \\
\text { decisões cotidianas do EES } \\
(68,1 \%)\end{array}$} & Sim & 42,9 & 57 & 60,7 & 39,3 & 49,8 & 50,2 \\
\hline & Não & 34,1 & 65,9 & 53 & 47 & 40,1 & 59,9 \\
\hline
\end{tabular}

Fonte: segundo Mapeamento Nacional 
Essas práticas internas também se coadunam com a participação sociopolítica, aumentando suas probabilidades. Ou seja, o envolvimento cotidiano dos sócios na vida do EES reflete-se positivamente nas três modalidades de participação sociopolítica. Em graus distintos, esse resultado se aplica à maioria das variáveis elencadas, com uma exceção, destacada em cor rosa na tabela 2.

Ambos os prismas de análise são globalmente complementares, no que respeita a aspectos institucionais e práticos da autogestão, convergindo quanto a seus efeitos sobre a participação sociopolítica dos EES. Indicam que a existência de mecanismos de participação nas decisões e de canais concretos de envolvimento dos associados na gestão, em assuntos financeiros (contratações, remunerações, prestação de contas) e estratégicos (planos de trabalho, etc.), guarda relação com a inserção dos EES em esferas coletivas mais amplas de articulação econômica, de mobilização e de atuação social. Com cifras ligeiramente diferentes, o exame dos dados do segundo Mapeamento ratifica, assim, as conclusões anteriores do primeiro Mapeamento (GAIGER, 2012).

\section{As lideranças dos EES formam uma elite?}

No espaço ainda disponível nesse artigo, voltamo-nos aos dados da pesquisa amostral sobre sócios e sócias dos EES, mencionada na Introdução. O objetivo, agora, consiste em buscar e avaliar evidências, ainda que sejam inconclusivas, relacionadas a um aspecto complementar às questões anteriores. Novamente, partimos de uma hipótese negativa:

Hipótese 5: a direção dos EES é restrita, ou altamente concentrada, em uma elite.

O conceito de elite já foi objeto de ampla literatura e mereceria uma longa discussão. Desde as primeiras formulações teóricas a respeito, por obra de Vilfredo Pareto (1848-1923) e Gaetano Mosca (1856-1941), como elites foram considerados grupos diferenciados, opostos às massas, cumprindo funções dirigentes. Detêm recursos, atributos simbólicos e posições de comando, com os quais concentram riqueza, poder e prestígio, o que lhes confere um status superior. Entre esses vários aspectos, nos interessa o fato de o acesso à condição de elite ser usualmente limitado em cada sociedade ou organização, por depender de recursos escassos ou exclusivos (econômicos, culturais, sociais) e estar sujeito a circuitos de autorreprodução das elites já estabelecidas. 
No caso dos EES, embora as diferenças sociais entre seus integrantes não se comparem àquelas observadas em nossa sociedade (KUYVEN, 2016), caberia tanto quanto possível verificar se suas lideranças formam um grupo cujas características são inacessíveis aos demais membros, não obstante os valores democráticos e igualitários preconizados pela Economia Solidária. Se assim for, a participação sociopolítica dos EES, geralmente delegada às suas lideranças, não espelharia a visão e a prática habitual da base social dessas organizações, mas seria obra de um segmento específico, possivelmente singular em relação à massa de integrantes dos EES. Em tese, esse estamento poderia, inclusive, valer-se dos envolvimentos sociopolíticos para galgar ou manter posições institucionais em benefício próprio, reproduzindo por essa via a sua posição peculiar, como foi salientado em um estudo paradigmático a respeito (WRIGHT MILLS, 1981).

Antes de ingressar nessa análise, propriamente, convém ater-se a alguns dados gerais da pesquisa amostral. Embora tenha sido realizada em 15 Unidades da Federação (14 Estados e o Distrito Federal), o número de questionários aplicados em cada região do país é proporcional ao de EES registrados no segundo Mapeamento. Porém, como a amostragem levou em conta o número de associados dos EES, em média maiores no espaço rural, há uma predominância de agricultores na amostra; ${ }^{14}$ e como nos EES rurais - e naqueles com atuação rural e urbana - prevalecem associados homens (representando o grupo familiar), resulta que esses figuram na amostra com $56 \%$, ao passo que as mulheres totalizam $44 \%$. Para $59 \%$ dos entrevistados, o ingresso no EES ocorreu entre 2001 e 2010, ao passo que $23 \%$ deles ingressaram antes, possuindo mais de 10 anos de experiência na Economia Solidária.

No total da amostra $(n=2.895)$, o movimento sindical é a participação sociopolítica pessoal mais frequente dos entrevistados, seja no período anterior $(22,5 \%)$ ou posterior (28\%) ao seu ingresso nos EES. Ela cresce entre os associados mais antigos (72\% dos ingressantes nos EES antes de 1980 são sindicalizados). A participação em fóruns e redes é a que mais cresce depois do ingresso nos EES (de 4\% para 10\%), enquanto permanece estável a atuação em organizações sociais e comunitárias (20\% × 23\%), em movimentos sociais ( $11 \%$ x 13\%) e em partidos políticos ( $9,5 \% \times 10)$.

${ }^{14}$ Que somam 50\%, havendo ainda 15\% de moradores de assentamentos da reforma agrária. 
Para fins de análise, podemos equiparar as lideranças dos EES às pessoas que exercem cargos de direção ou de representação. No referente a funções no âmbito dos EES (direção geral do EES, coordenação de setores ou representação externa), 26\% dos associados declararam tê-las exercido. Já os cargos que vão além das fronteiras dos EES envolvem parcelas menores de associados: $14 \%$ em instâncias locais, $8 \%$ em órgãos regionais ou estaduais e $3 \%$ em esferas ou eventos nacionais ou internacionais. Para verificar se esses associados formam um segmento à parte, sociologicamente equiparável a uma elite, comparamos o seu perfil econômico, social e cultural com aquele da totalidade dos sócios e sócias, distinguindo dois níveis: média liderança (direção geral do EES; representação externa do EES; presença em organizações locais), num total de 1.137 associados (39\%); alta liderança (cargos em organizações regionais, estaduais, nacionais ou internacionais), exercida por 249 associados ( $9 \%)$.

Colocando em paralelo o perfil da totalidade de associados com aquele da liderança, observa-se uma similaridade entre os percentuais do sexo masculino e feminino, mantendose nas lideranças uma distribuição semelhante àquela apurada para o conjunto de associados ( $56 \%$ de homens e $44 \%$ de mulheres na totalidade da amostra; $58 \%$ × 42\% no caso da média liderança; $56 \%$ × 44\% na alta liderança). Contudo, a composição etária da liderança destacase por um percentual maior de indivíduos entre 31 a 60 anos ( $87 \%$ na alta liderança e $75 \%$ na média, contra $71 \%$ no total da amostra) e menor no tocante a indivíduos até 30 anos ( $2 \%$ na alta liderança e 10\% na média, enquanto na totalidade da amostra o percentual é de 15\%). Portanto, as lideranças são proporcionalmente mais velhas do que os associados sem essas funções.

Não há variação expressiva entre líderes e não líderes quanto ao pertencimento a povos tradicionais. No quesito étnico-racial, porém, o percentual de brancos cresce linearmente do total de associados para a alta liderança (de 38,5\% para 45,5\%), enquanto decresce aquele de negros, pardos e mulatos (de 57,5\% para 53\%). Mais nítido é o incremento do nível de escolaridade, no tocante a saber ler e escrever sem dificuldades (de $65 \%$ no total da amostra para $84 \%$ na alta liderança) e também a ter completado o ensino médio ${ }^{15}$ (de $32 \%$ para $47 \%)$.

\footnotetext{
${ }^{15}$ Nas modalidades de ensino científico, clássico ou profissional.
} 
Uma análise a respeito separou a participação sociopolítica em dois tipos: participação mais social (em fóruns e redes e em organizações sociais ou comunitárias; $n$ = 824) ou mais política (movimento sindical, movimentos sociais e partidos políticos; $\mathrm{n}=1.091$ ). No primeiro caso, as variações relativas à presença de brancos e de negros, pardos e mulatos ocorrem em proporção menor do que as antes mencionadas, assim como aquelas relativas à escolaridade. No segundo caso, de participação mais política, as variações não se distanciam do padrão geral, exceto no que diz respeito à maior presença do sexo masculino (66\%) em relação ao feminino (34\%). Um elemento explicativo reside na frequência maior de lideranças desse tipo entre agricultores ( $59 \%$, contra $46 \%$ na totalidade da amostra), o que se reflete na predominância de moradia em zona rural $(77 \%$ × 60\%). O fato remete ao grau de organização dos agricultores familiares, especialmente via sindicatos rurais nos quais a presença masculina, ao menos no plano formal, tem sido preponderante. Esse aspecto é congruente com o percentual maior de associados politicamente participantes que haviam ingressado nos EES há pelo menos 12 anos antes da pesquisa (31,5\%, contra $23 \%$ no total da amostra), haja vista que as vertentes mais antigas da Economia Solidária se encontram no campo (GAIGER et al, 2014: 96-110). ${ }^{16}$

Na realidade brasileira, as diferenças de participação em cargos de chefia, liderança e outros afins, entre brancos e não brancos, ou entre pessoas com diferentes graus de escolaridade, além daquelas relativos a sexo, são consabidamente gritantes. No caso da Economia Solidária, ainda que a distância entre as cifras não seja discrepante e não configure um caso de elitismo, nota-se a influência de fatores socioculturais prévios, típicos do quadro de desigualdades agudas reinante no Brasil, que não deixam de afetar grau de protagonismo de associados e associadas dos EES.

Em relação à influência de aspectos relacionados ao tipo de atividade econômica exercida pelos associados nos EES - ou seja, a seu protagonismo econômico intramuros na Economia Solidária - o primeiro fato saliente é que há poucos líderes sem nenhuma ocupação propriamente econômica (10,5\%). A proporção de associados cuja renda principal vincula-se aos EES se mantém estável entre a base e as lideranças (aumentando de 30\% para apenas

${ }^{16}$ O estudo em questão é de autoria de Felipe Friedrich da Silva, bolsista de Iniciação Científica citado na nota 1. 
31,5\%). Contudo, observa-se que, da base ao topo, há uma queda no percentual de associados cuja renda pessoal não depende do EES (de $37 \%$ para $25 \%$ ) e um aumento daqueles para quem o EES propicia uma renda complementar (de 33\% para 43\%), de sorte que possuem outras ocupações concomitantes ou dispõem de outras fontes de renda, como pensões e aposentadorias. No caso das lideranças, a atividade laboral externa aos EES apresenta uma tendência, mesmo tênue, ${ }^{17}$ de melhora nas condições de trabalho e renda: em proporção ligeiramente maiores, elas exercem uma atividade remunerada independente do EES, usufruindo de remuneração fixa ou proporcional à jornada de trabalho em percentuais maiores que os demais (ao passo que diminui a remuneração por produção ou comissões), em valores monetários também ligeiramente superiores.

Pode-se, então, inferir que o perfil de envolvimento econômico das lideranças combina atividades regulares na Economia Solidária com maior grau de autonomia e de segurança econômica pessoal. Essa condição favorece o exercício da liderança à medida que tais funções normalmente requerem maior flexibilidade e disponibilidade de tempo ou, mesmo, o empenho de recursos pessoais para custear viagens e outras despesas. A Economia Solidária não criaria, ela mesma, tais condições propícias ao exercício da liderança, mas seria por ela beneficiada.

Essa condição relativamente favorável das lideranças explicaria que as motivações de uns e outros para atuar na Economia Solidária não sejam exatamente as mesmas: as lideranças mostram-se mais identificadas com os valores da Economia Solidária, deixando em segundo plano os ganhos e compensações materiais. Nos três estratos, mas de forma crescente quando se vai dos dados gerais para aqueles da média e da alta liderança, despontam em primeiro lugar motivações ligadas ao fortalecimento da comunidade e dos movimentos sociais ( $90 \%$ na alta liderança) e à participação em uma atividade coletiva (89\%), motivações reforçadas pelo "acreditar na economia solidária" (83\%). Em segundo lugar, aparecem motivos ligados a aspirações pessoais: "trabalhar no que eu gosto" (84\%), melhorar minha renda ou meu nível de vida (82\%) e trabalhar com mais comodidade quanto ao horário e local (66\%). Em terceiro lugar ficam motivações associáveis a necessidades ou

\footnotetext{
${ }^{17}$ A diferença de percentuais raramente ultrapassa $4 \%$ nos aspectos mencionados a seguir.
} 
vantagens individuais: evitar o desemprego e dispor do apoio de entidades ou do governo (ambas com 59\%).

Como, de todo o modo, essas cifras mais uma vez não se distanciam, seria implausível concluir que existam dois universos, separando base social e liderança por razões materiais ou ideológicas. Os dados indicam, antes, um gradiente em que condições materiais, graus de disponibilidade e motivações combinam-se variavelmente. Eles apontam uma tendência das lideranças a valorizarem questões de princípio, alinhadas aos valores propugnados pelo movimento social da Economia Solidária e seus diversos apoiadores.

\section{Considerações finais}

Passando em revista os resultados da análise, é justo considerar como significativa a participação sociopolítica dos EES, pela frequência com que ocorre e por ser diversificada e múltipla. Os espaços institucionais de participação indicam que a mesma se refere amiúde a questões de interesse coletivo, atinentes a modalidades de articulação e cooperação, assim como ao atendimento de demandas sociais de distintas ordens. Esses envolvimentos não são algo peculiar aos EES jovens, presumivelmente movidos por maior entusiasmo, posto que persistem ao longo do tempo. Eles dizem respeito a espaços de mobilização em que atuam organizações populares e entidades de apoio por vezes com larga trajetória, em compasso com causas e frentes de atuação mais recentes, em evidência, principalmente, no segundo Mapeamento, como aquelas dos povos tradicionais, dos artesãos e das mulheres.

Há alguns indícios de que EES com acesso ao mercado e a mecanismos convencionais de suporte e financiamento, entre outros, tendem a arrefecer sua mobilização sociopolítica. No entanto, não ao ponto da simples desmobilização. Uma condição vantajosa desse ponto de vista - mutatis mutandis também no caso de associados providos de melhores condições de trabalho e renda, escolarização e experiência - redunda, por vezes, em novos engajamentos, seja em prol de causas sociais mais amplas, seja assumindo cargos e responsabilidades de liderança. Nas circunstâncias estudadas, a mobilização social e política não reflete apenas uma atitude altruísta, e muito menos diletante, mas constitui uma via efetiva de resolução de problemas concretos. Isto não significa que prevaleçam posturas utilitaristas, direcionadas a vantagens particulares, em detrimento dos demais. Em continuidade à análise realizada sobre os dados do primeiro Mapeamento (GAIGER, 2012), 
têm-se elementos consistentes em favor da hipótese (desta vez, positiva) de que a Economia Solidária foi um dos esteios de conformação de um campo ético-político e de impulsão de redes movimentalistas - retomando conceitos do trabalho inspirador de Ana Maria Doimo $(1995)^{18}$ - com poder de agregação e mobilização social. Essa disposição a agir coletivamente seria alimentada pela capacidade de tais iniciativas em gerar confluências a partir da diversidade, de formar consensos em torno da agenda pública, de formar militantes, atraindo e propiciando interações entre trabalhadores, agentes mediadores e atores políticos. A julgar pelas variadas intersecções de causas e atores que se manifestam no interior da Economia Solidária e nas suas frentes sociopolíticas de ação, ela cumpriria um papel de desaguadouro de demandas e expectativas, de espaço de convergências transversal a organizações específicas e a aos movimentos populares que emergiram ou se destacaram nas últimas décadas.

Certamente, conviria dar mais robustez a essa conclusões gerais, refinando as análises e identificando situações em que as correlações positivas são mais fortes, ou mais tênues: elas poderiam variar com os tipos de EES (GAIGER et al,2014), com suas atividades econômicas, seu porte e forma de organização ou, ainda, com o tempo de funcionamento dos EES ou de experiência pessoal de seus membros. Isto permitiria avançar para uma análise mais segura sobre casos de dependência entre as variáveis e de existência de causalidade entre elas. Fazê-lo demonstraria uma vez mais o valor de bases de dados representativos para que possamos dimensionar e compreender a fisionomia das experiências alternativas e as forças que as impulsionam, em seus diversos contextos. Explorações dos dados do SIES integradas a análises qualitativas seriam certamente de grande valia, podendo render estudos monográficos sobre algumas opções de envolvimento sociopolítico que se destacam à luz dos dados gerais. Bastaria ter vista casos notórios, como a Rede Ecovida, a Rede Abelha, a Rede Lixo e Cidadania, redes de mulheres e de agroecologia, como, também, inúmeros conselhos municipais ou regionais de desenvolvimento rural sustentável, da criança e do adolescente, do idoso, de saúde e, ainda, de segurança alimentar.

\footnotetext{
${ }^{18}$ Obra ainda atual, resultante do prêmio "José Albertino Rodrigues", da ANPOCS, de melhor tese em Ciências Sociais de 1994 .
} 
Lançar um olhar global sobre a Economia Solidária (GAIGER, 2014) ganha talvez maior relevância nos dias atuais, dada a ruptura e o refluxo das políticas públicas que antes lhe davam suporte e, ademais, as tentativas governamentais de imobilização ou de desmantelamento dos conselhos participativos e demais estruturas que garantiam a existência de uma rede de proteção social, cujas inegáveis dificuldades não desmerecem sua crucial importância. A letargia inicial que involuntariamente se instalou entre seus promotores diante dessas bruscas mudanças, sem contudo tê-los condenado à desmobilização, propicia também espaços para avaliações mais serenas e distanciadas dos fatos, o que requer uma visão retrospectiva e abrangente. Nesse mesmo aspecto da participação sociopolítica, ou com propósitos mais específicos, estudos sobre os dados dos Mapeamentos mostram-se fecundos, mesmo após anos transcorridos desde os eventos políticos de 2016. Embora tais estudos não sejam frequentes, não faltam bons exemplos (SCHNEIDER, 2010; KUYVEN, 2016; DIEESE, 2015, 2017; BOSSLE et al, 2017). Tais informações registram a emergência e a expansão de variadas iniciativas sociais de resistência e de contraposição à lógica deletéria do capitalismo; essas iniciativas, ao mesmo tempo, constituem um legado dos tantos atores sociais que tornaram aquelas iniciativas visíveis e dignas de crédito. De resto, a considerar a multiplicidade de intersecções sociopolíticas, a partir da Economia Solidária ou em sua direção, fica patente que ela esteve cumprindo um papel de desaguadouro de demandas e aspirações, funcionando como um espaço de convergência entre organizações e movimentos populares que emergiram ou se destacaram nas últimas décadas, materializando e se colocando em defesa da democracia em nosso país.

\section{Referências}

BOSSLE, M. et al. Fair trade in Brazil: current status, constraints and opportunities. Organizações \& Sociedade, v. 24, n. 83, p. 655-673, 2017.

CATTANI, A. et al. (Org.) Dicionário internacional da outra economia. Coimbra: Almedina, 2009.

WRIGHT MILLS, C. 4. ed. A elite do poder. Rio de Janeiro: Zahar Editores, 1981.

DEFOURNY, J.; NYSSENS, M. (Dir.). Économie sociale et solidaire. Socioéconomie du $3^{\text {ème }}$ secteur. Louvain-la-Neuve: De Boeck Supérieur, 2017. 
DOIMO, A. A vez e a voz do popular: movimentos sociais e participação política no Brasil pós-70. Rio de Janeiro: Relume Dumará; ANPOCS, 1995.

DIEESE. Informalidade na economia solidária. São Paulo: DIEESE, 2015. (Coleção Cadernos de Debates do Observatório Nacional da Economia Solidária e do Cooperativismo, n. 1).

DIEESE. A comercialização na economia solidária em empreendimentos urbanos de produção artesanal liderados por mulheres. São Paulo: DIEESE, 2017. (Coleção Cadernos de Debates do Observatório Nacional da Economia Solidária e do Cooperativismo, n. 2).

FONTENEAU, B. et al. Economía Social y Solidaria: nuestro camino común hacia el trabajo decente. Turim: Centro Internacional de Formação da OIT, 2011.

GAIGER, L. A economia solidária no Brasil e o sentido das novas formas de produção não capitalistas. Cayapa - Revista Venezolana de Economía Social, v. 4, n. 8, p. 9-37, 2004.

GAIGER, L. A outra racionalidade da economia solidária. Conclusões do Primeiro Mapeamento Nacional no Brasil. Revista Crítica de Ciências Sociais, n. 79, p. 57-77, 2007.

GAIGER, L. A presença política da economia solidária: considerações a partir do primeiro mapeamento nacional. In: Márcia Leite; Isabel Georges (Org.). Novas configurações do trabalho e economia solidária. São Paulo: Annablume, p. 289-321, 2012.

GAIGER, L. Conhecer globalmente: um desafio inadiável dos estudos sobre a economia solidária. Otra Economía, v. 8, n. 14, p. 101-113, 2014.

GAIGER, L. A descoberta dos vínculos sociais. Os fundamentos da solidariedade. São Leopoldo: Editora Unisinos, 2016.

GAIGER, L. et al. A economia solidária no Brasil: uma análise de dados nacionais. São Leopoldo: Oikos, 2014.

GAIGER, L.; FERRARINI, A.; SCHIOCHET, V. O estado da arte e agenda de pesquisa sobre a Economia Solidária no Brasil. Revista Brasileira de Sociologia, v. 6, n. 12, p. 157-180, 2018.

GUERRA, P. Socioeconomia de la solidaridad. Montevideo: Nordan-Comunidad, 2002.

KUYVEN, P. Efeitos da economia solidária sobre a geração de renda e a redução da pobreza: um estudo de dados nacionais. 2016. Tese (Doutorado) - Programa de Pós-graduação em Ciências Sociais, Universidade do Vale do Rio dos Sinos, 2016.

LAVILLE, J.-L. Solidarité. In: LAVILLE, J.-L.; CATTANI, A. (Ed.). Dictionnaire de l'autre économie. Paris : Desclée de Brouwer, p. 491-498, 2005.

LEITE, M. A economia solidária o trabalho associativo: teorias e realidades. Revista Brasileira de Ciências Sociais, v. 24, n. 69, p. 31-51, 2009.

LIMA, J. Cooperativas, trabalho associado, autogestão e Economia solidária: a constituição do campo de pesquisa no Brasil. In: GEORGES, I.; LEITE, M. (Org.). Novas configurações do trabalho e economia solidária. São Paulo: Annablume, 2012. p. 195-221. 
NAMORADO, R. Cooperativismo - história e horizontes. Estudos de Direito Cooperativo e Cidadania. Curitiba, v.1, p. 9-35, 2007.

PINHO, C. Planejamento estratégico governamental no Brasil. Autoritarismo e Democracia (19302016). Curitiba: Appris, 2019.

RAZETO, L. Los caminos de la economía de solidaridad. Buenos Aires: Editorial LumenHvmanitas, 1997.

SCHNEIDER, E. As potencialidades da economia solidária na redução das desigualdades de gênero. Protestantismo em Revista, n. 23, p. 11-20, 2010.

SINGER, P. Uma utopia militante. 2. ed. Petrópolis: Vozes, 1999.

\section{Dados do autor}

Luiz Inácio Gaiger

Doutor em Sociologia, docente do Programa de Pós-graduação em Ciências Sociais da Universidade do Vale do Rio dos Sinos e Bolsista de Produtividade do CNPq, a quem se reconhece esse apoio desde 2000 e diversos auxílios à pesquisa. Esse trabalho contou com a colaboração de Felipe Friedrich da Silva, graduando em Ciências Sociais e Bolsista de Iniciação Científica (PIBIC/CNPq) no período 08/2018 - 07/2019. E-mail: gaiger@unisinos.br. ORCID iD https://orcid.org/0000-0003-0241-7064. 